\title{
Genome-Wide Characterization of B-BOX Gene Family and Their Responses to Light Quality and Cold Stress in Tomato
}

\section{Xin Bu}

Shenyang Agricultural University

\section{Xiujie Wang}

Shenyang Agricultural University

Jiarong Yan

Shenyang Agricultural University

Ying Zhang

Shenyang Agricultural University

\section{Shunyuan Zhou}

Shenyang Agricultural University

\section{Xin Sun}

Shenyang Agricultural University

\section{Youxin Yang}

Jiangxi Agricultural University

\section{Golam Jalal Ahammed}

Henan University of Science and Technology

\section{Yufeng Liu}

Shenyang Agricultural University

\section{Tao Xu}

Shenyang Agricultural University

Hongyan Qi

Shenyang Agricultural University

\section{Mingfang Qi}

Shenyang Agricultural University

\section{Feng Wang ( $\nabla$ fengwang@syau.edu.cn )}

Shenyang Agricultural University https://orcid.org/0000-0001-5351-1531

\section{Tianlai Li}

Shenyang Agricultural University 
Keywords: Tomato, BBX, Light quality, Low temperature

Posted Date: October 1st, 2020

DOI: https://doi.org/10.21203/rs.3.rs-64408/v1

License: (c) (1) This work is licensed under a Creative Commons Attribution 4.0 International License. Read Full License 


\section{Abstract}

Background: Perceiving incoming environmental information is critical for optimizing plant growth and development. Multiple B-box proteins (BBXs) play essential roles in light-dependent developmental processes in plants. However, whether BBXs function as a signal integrator between light and temperature in tomato plants remains elusive.

Results: In this study, 31 SIBBX genes were identified from the newly released tomato (Solanum lycopersicum) genome sequences, and were clustered into five subgroups with phylogenetic analysis. Gene structure and protein motif analyses showed relatively high conservation of closely clustered SIBBX genes within each subgroup; however, genome mapping analysis indicated the uneven distribution of the $S I B B X$ genes on tomato chromosomes. Synteny analysis indicated that segmental duplication events happened in the expansion of the $S / B B X$ genes in tomato. Promoter cis-regulatory elements prediction indicated that $S I B B X$ genes were highly responsive to light, hormones, and stress conditions. Furthermore, the transcript analysis revealed that various $S / B B X$ genes differed significantly in expression after exposure to different light quality and low temperatures, while $61.3 \%$ of $S I B B X$ genes were responsive to both light and low temperatures.

Conclusions: Our study presented a genome-wide survey of SIBBX gene family in tomato, and emphasized their functions in perceiving light quality and low temperature, which may improve the current understanding of SIBBX gene functions in integrating light and temperature signals for plant adaptation to adverse environments.

\section{Background}

The B-box (BBX) proteins represent a unique class of zinc-finger transcription factors (TFs) that possess single or double B-box domains in their $\mathrm{N}$ termini and a CCT (CO, CO-like and TOC1) domain in their $\mathrm{C}$ termini in some cases [1]. The B-box domains are of two classes, and each of them coordinates two zinc atoms [2]. The dissimilarities in the consensus sequences of the two B-box domains are the results of evolution through the segmental duplication and deletion events[3]. Studies suggest that the highly conserved CCT domain is important for transcriptional regulation and nuclear transport [4]. Furthermore, the valine-proline (VP) motif of six amino acids (G-I/V-V-P-S/T-F) contained by some BBX proteins, plays a crucial role in the interaction with CONSTITUTIVELY PHOTOMORPHOGENIC 1 (COP1) $[5,6]$. Based on the domain structures, $32 \mathrm{BBX}$ proteins are divided into five subfamilies in Arabidopsis $[1,3]$.

A variety of wavelength-specific photoreceptors are involved in perceiving the light signals in plants, including phytochromes (phys), cryptochromes (CRYs), phototropins (PHOTs), ZEITLUPE family members, and UV-B resistance locus 8 (UVR8) [7, 8]. Light-activated photoreceptors inhibit the COP1SUPPRESSOR OF PHYA-105 (SPA) E3 ubiquitin ligase complex, which functions for the degradation of the positive regulators of photomorphogenesis [7, 8]. Notably, HY5, a target of COP1-mediated protein degradation, plays a vital role in light-regulated plant growth and development $[9,10]$. Thus, the light- 
dependent regulation of COP1-HY5 mediates the plant developmental transition from dark to light. Recent studies have demonstrated that numerous BBX proteins, along with COP1 and HY5, play critical roles in light-dependent development in plants.

Upon light irradiation, $\mathrm{BBX} 21$ directly binds to $B B X 22, H Y 5$ and its own promoter regions and activates their transcription [11-13]. Moreover, both BBX21 and HY5 can associates with the $B B X 11$ promoter to promote its transcription, while BBX11 binds to the $H Y 5$ promoter to activate its transcription [14]. Thus, these three TFs (BBX21, HY5 and BBX11), regulate the transcription, forming a positive feedback loop that precisely regulates plants photomorphogenesis. Moreover, BBX20, BBX21, BBX22 and BBX23 interact with HY5 to increase its transcriptional activity toward the target genes [15-17], whereas BBX24, BBX25, BBX28 and BBX29 suppress photomorphogenesis by reducing the activity of HY5 [17-20]. The HY 5 positively controls $B B X 22$ at the transcriptional level [21], whereas it represses the transcription of $B B X 30$ and $B B X 31$ by binding to the promoters of these two genes $[22,23]$. Meanwhile, BBX30 and $\mathrm{BBX} 31$ promote the expression of $B B X 28$ and $B B X 29$ by directly binding to the promoter regions of these genes [20]. In addition, direct interactions between BBX32 and BBX21 lead to inhibition in the BBX21-HY5 [24]. Interestingly, BBX4, accumulated after exposure to red light, directly interacts with phyB to promote photomorphogenesis in Arabidopsis [25]. These mechanisms are also found in other plant species. For example, OsBBX14 induces OsHY5L 1 gene expression to stimulate photomorphogenesis in rice [26]. MdBBX37 associates with MdHY5 promoter to inhibit its expression in apple [27]. Additionally, MdBBX22 and MdBBX25/MdCOL4 bind to the MdHY5 promoter to increase and decrease the transcriptional activation of MdHY5, respectively [28]. Both PpBBX16 and PpBBX18 interact with PpHY5 to increase the biochemical activity of PpHY5, while PpHY5 binds to the promoter region of PpBBX18 to promote the transcription of $P p B B X 18$ in pear $[29,30]$. Furthermore, the interaction of PpBBX21 with PpHY5 and PpBBX18 affects the bioactive heterodimers formation of PpHY5-PpBBX18 [30]. Therefore, specific BBXs and HY 5 constitute an important regulatory network to precisely control normal plant growth and development.

In darkness, CO/BBX1, BBX4, BBX10, BBX19, BBX20, BBX21, BBX22, BBX23, BBX24, BBX25, BBX28 and $B B X 29$ are ubiquitinated by COP1 and subsequently degraded by the $26 S$ proteasome system $[11,16$, 18-20, 22, 31-33]. Moreover, BBX2-9 and BBX13-16 interacts with COP1 in vitro, indicating a role for COP1 in controlling the stability of these proteins in darkness [33]. Nevertheless, COP1 preferentially stabilizes BBX11 instead of promoting its degradation [14], which suggests that COP1 likely regulates a yet unidentified protein degradating BBX11.

BBX proteins also act vital roles in regulatory networks that control plant adaption to abiotic stress. Previous studies show that both BBX5 and BBX21 positively regulate plants tolerance to drought and salt stress in Arabidopsis [34, 35]. BBX24/STO directly interacts with H-protein promoter binding factor 1 (HPPBF-1), which is a salt-responsive MYB TF, to enhance the root growth and salt tolerance in Arabidopsis [34]. CmBBX22 also positively regulates the plant drought tolerance [36]. In addition, MdBBX10 enhances tolerance to salt and drought by modulating ABA signaling and ROS accumulation [37]. In Arabidopsis, BBX18 and BBX23 control thermomorphogenesis [38]. Both MdBBX20 and MaCOL1 
are responsive to low temperatures in apple and banana, respectively $[39,40]$. Furthermore, $Z F P L$, a homologous gene of $A t B B X 32$, enhances cold tolerance in the grapevine [41]. CmBBX24 also increases plant cold tolerance in Chrysanthemum [42]. However, whether SIBBXs are involved in light and cold response in tomato remains to be explored.

In the present study, 31 SIBBX genes were identified and characterized in tomato. Gene distribution, synteny analyses, the architecture of exon-intron and motifs differences were investigated. Furthermore, the three-dimensional structure and evolution of SIBBX proteins were performed. Promoter analysis showed that the cis-elements in light signaling, hormones and stress response were the main elements of $S I B B X s$ promoters. Meanwhile, we found that multiple SIBBX genes were either up-regulated or downregulated in response to different light quality and low temperatures, and $61.3 \%$ of $S / B B X$ genes were responsive to both light and low temperatures. Therefore, our results suggest that SIBBXs are an essential component of light and temperature cues, which function to integrate environmental stimuli and plant hormones to coordinate plant growth under low temperatures.

\section{Results}

\section{Identification and characterization of SIBBX Genes in tomato}

Based on the gene annotation as well as the conserved B-box motif characteristic of the BBX members, a total of 31 SIBBX genes were identified. The detailed information [gene name, gene identifiers, chromosome location, theoretical isoelectric point (pl), molecular weight (MW), genomic, coding sequences (CDS), peptide length, number of exon and intron, instability and aliphatic index, the grand average of hydropathicity (GRAVY) values and subcellular localization) of each SIBBX was presented in Table 1. The lengths of CDS and amino acids (AA) of 31 SIBBXs range from $267 \mathrm{bp}$ and 88 aa (SIBBX18) to $1428 \mathrm{bp}$ and 475 aa (SIBBX27), respectively. Thus, varied MW and pl were observed among SIBBX proteins. The MW of SIBBXs varies from 9.57 (SIBBX18) to $53.14 \mathrm{kDa}$ (SIBBX27). The pl ranged from 4.25 (SIBBX5 and SIBBX7) to 9.28 (SIBBX26), with 74.2\% SIBBXs with a pl lower than seven, which indicated that most of the SIBBX proteins were acidic in nature. The pl ranged from 4 to 9 in SIBBX proteins contained one (single) or two (double) B-box domains, while it decreased when plus a CCT domain, especially in the SIBBX proteins with a B-BOX domain plus a CCT domain (Additional file 1: Figure S1), which suggested that the CCT domain in SIBBX proteins may decrease their pl. Majority of SIBBXs were grouped into unstable proteins because their instability index was greater than 40 , except for SIBBX6 in this family (Table 1). The predicted aliphatic index ranged from 50.05 to 97.43 in SIBBX proteins. All SIBBX proteins, with the exception of SIBBX18, were predicted to be hydrophilic due to the GRAVY value $(<0)$. Subcellular localization predicted that most SIBBXs (23 of 31) were localized in the nuclear region, five of them, including SIBBX5, SIBBX 6, SIBBX17, SIBBX25 and SIBBX31 in the chloroplast, while SIBBX16 and SIBBX18 in the cytoplasm, SIBBX19 in the peroxisome (Table 1). In 
addition, none of the $31 \mathrm{BBX}$ proteins have a transmembrane domain, which indicated that these SIBBX proteins were not located on the cell membrane (Additional file 1: Figure S2).

\section{Protein sequences, phylogenetic analysis and three- dimensional structure of SIBBXs}

The domains logos and the sequences of the B-box1, B-box2 and CCT domain of the SIBBX proteins are shown in Fig. 1. Eight members out of the 31 SIBBXs, were characterized by the occurrence of two B-box domains and also a conserved CCT domain, whereas four members of them had a valine-proline (VP) motif (Table 2). Only two B-BOX domains were found in ten SIBBXs, whereas five members had one B-box domain and also a CCT domain, and eight members had only one B-box domain (Table 2). Among the three domains, we found that each tomato B-box motif contained approximately 40 residues with the consensus sequence C-X2-C-X8-C-X2-D-X4-C-X2-C-D-X3-H-X8-H (Fig. 1). The conserved C, C, D and H residues ligated two zinc ions [2]. Additionally, the consensus sequence of the conserved CCT domain was R-X5-R-Y-X-E-K-X3-R-X3-K-X2-R-Y-X2-R-K-X2-A-X2-R-X-R-X-K-G-R-F-X-K (Fig. 1).

To better reveal the evolutionary relationships, we generated a phylogenetic tree based on the 32 AtBBXs and 31 SIBBXs (Fig. 2). All sequences were clustered into five subfamilies according to the phylogenetic analysis and previous article [2]. The BBX genes in clade I (group 1) had two concatenated B-box domains, a CCT domain and a VP motif except for SIBBX1 and SIBBX2, which did not have a VP motif and a CCT domain. The members of group II were characterized by two B-box domains and also a CCT domain with the only exception for SIBBX7, which contained two B-box domains only, and SIBBX8 and SIBBX10, which only had one B-box domain and a CCT domain. In the group III, all the members contained one B-box domain as well as a CCT domain. The group IV and V possessed two and one B-box domain, respectively; nonetheless, SIBBX27 that contained two B-box was also grouped into V. Additionally, BBX proteins from two species showed scattered distribution across the branches of the evolutionary tree, which implies that the duplication events occurred after the lineages diverged.

Protein structural features are crucial for understanding the biological properties as well as the evolutionary origins of proteins. Here, we found that most members of SIBBX proteins in a subfamily had a similar three-dimensional structure (Fig. 3). In addition, we found physical connections in each protein sector in the tertiary structure. Moreover, a distinct functional role, and an independent mode of sequence divergence in the protein family, reflected the evolutionary histories of the conserved biological properties of BBX proteins.

\section{Gene structure, conserved motifs, chromosomal localization and synteny analysis of SIBBXs}

The evolution of multigene families can be driven by gene structural diversity. Examination of the genomic DNA sequences revealed that most SIBBXS contained one to five introns, while SIBBX16, 
SIBBX17 and SIBBX30 had no introns (Fig. 4b and Table 1; Additional file 1: Figure S3). Among them, nine $S I B B X s$ had one intron, followed by ten SIBBXS with two introns, five SIBBXS with three exons, four SIBBXS with four exons, and one SIBBXS with five introns. Generally, members of each subclass, which are most closely related, exhibited analogous exon-intron structures. For instance, the members in group I and $\mathrm{V}$ had one to two, and zero to one intron, respectively (Fig. 4a and 4b; Additional file 1: Figure S3). However, a few SIBBX genes showed dissimilar exon-intron arrangements. For instance, SIBBX18 and SIBBX19 had high sequence similarity, but $S / B B X 18$ and $S I B B X 19$ contained two and five introns, respectively (Fig. 4a and 4b; Additional file 1: Figure S3). These divergences indicated that both the gain and loss of introns during evolution, may better explain the functional diversity of SIBBX homologous genes.

To further examine the structural features of SIBBXs, the conserved motif distributions were analyzed. Twenty conserved motifs were predicted (Fig. 4C), while multilevel consensus sequences and the E-value of them were shown in Additional file 2: Table S1. The results showed that motif 17 was the largest motif depending on the width, followed by motif 8 and motif 2 (Additional file 2: Table S1). Motif 1 was found in all the SIBBXs (Fig. 4C). Notably, 74.2\% and 70.1\% SIBBXs contained motif 4 and motif 3, respectively. Motif 2 was unique to the group I, II and III of SIBBXs, while motif 5 was unique to group II except for the SIBBX27. Motif 10 was found only in group III of SIBBXs. Our results showed that members that are most closely related in the phylogenetic tree contained common motifs on the basis of alignment and position, which indicated that they may have a similar biological function.

Chromosomal locations showed that 31 SIBBX genes were unevenly distributed on the 12 chromosomes (Fig. 5a). A maximum number of SIBBX genes were found on chromosome 12 (Chr12), comprising of six genes. Five genes were located on Chr2 and Chr7. Four and three SIBBX genes were located on Chr5 and Chr4, respectively. Both Chr1 and Chr6 contained two members of SIBBX genes, whereas only one gene was detected on Chr3, 8, 9 and 10. Additionally, no SIBBX genes were found on Chr11.

To examine the duplication of SIBBX genes, the MCScanX program was used. Thirty-six pairs of SIBBXs were identified as segmental duplication in the tomato genome (Fig. 5b). Chr2, 7 and 12 had more duplication regions, which partially explain the greater numbers of $S / B B X$ genes that were located on these three chromosomes. Although SIBBX1 and SIBBX3 were located on the same chromosome (Fig. 5a), and their sequence identity was $83 \%$ (Additional file 1: Figure S4), they were not tandem duplication. To further examine the evolutionary relationships between SIBBXS and AtBBXs, a synteny analysis was performed with MCScanX software. A total of 16 of SIBBX-AtBBX orthologous pairs were identified (Fig. 5C), which indicated the existence of numerous SIBBX genes prior to the divergence of Arabidopsis and tomato. Some members of $S / B B X S$ were not localized in the syntenic block, suggesting that these genes might have certain specificity due to their evolution time.

\section{Analysis of cis-elements in the promoter region of SIBBXs}

Transcription factors directly bind the cis-elements in regulatory networks controlling gene expression; therefore, analysis of the putative cis-elements is critical to examine the expression of SIBBX genes. A 
total of 61 major cis-elements were predicted from the PlantCARE database (Fig. 6a), including 22 light responsive, 12 hormone responsive, 11 stress responsive and 16 development. The number of light responsive cis-elements was the largest in the promoters of 31 SIBBX genes (Fig. 6b). The number of ciselements in the promoters of $S / B B X 17$ and $S / B B X 2$ was the largest and least, respectively. The major light responsive elements contained box4 (21\%), G-box (17.9\%) and CMA1a/2a/2b (14.3\%), which were located on $87.1 \%$ (27/31), 83.9\% (26/31) and 96.8\% (30/31) of SIBBXS promoters, respectively (Fig. 6C). The most common motif were the JA-responsive elements (MYC), abscisic acid (ABA)-responsive element (ABRE), and ethylene-responsive element (ERE), accounting for $24.8 \%, 21.5 \%$ and $17.2 \%$ of the scanned hormone responsive motifs, respectively. The stress responsive elements MYB, STRE (stressrelated elements) and WUN were located on $96.8 \%$ (30/31), 90.3\% (28/31) and $77.4 \%$ (24/31) of 31 $S / B B X$ genes promoters, respectively. In the development category, various growth and development related elements, such as AT-rich element (19.2\%), $\mathrm{O}_{2}$-site for zein metabolism regulation $(13.7 \%)$, CATbox for meristem expression (12.3\%), GCN4_motif required for endosperm expression (9.6\%), were found. Our findings suggest that the promoter regions of $S I B B X$ genes that contained the cis-elements played a critical role in the light and stress responses.

\section{SIBBX genes expression in response to different light quality}

To assess whether light signaling regulates $S / B B X S$, we investigated the gene expression of $S / B B X s$ in tomato plants grown at dark (D), white (W) and different light quality [purple (P), blue (B), green (G), yellow $(Y)$, red $(R)$, and far-red $(F R)$ ] conditions. In comparison with $D$, light decreased the transcripts of $S I B B X 1, S / B B X 8, S I B B X 10$ and $S \mid B B X 12$, while it increased the transcripts of $S / B B X 7, S I B B X 13$ and $S I B B X 15$ (Fig. 7). Plants grown at $\mathrm{R}$ light conditions showed higher expression of SIBBX4, SIBBX14, $S I B B X 23, S I B B X 24$ and $S I B B X 29$ than those grown at other light qualities. Whereas FR light significantly up-regulated the transcripts of $S / B B X 7, S I B B X 13, S / B B X 15, S / B B X 21, S / B B X 25$, SIBBX26 and SIBBX27, it obviously down-regulated the transcripts of SIBBX14, SIBBX16, SIBBX18, SIBBX24, SIBBX28, SIBBX30 and SIBBX31 (Fig. 7). Transcripts of SIBBX16, SIBBX17, SIBBX18, SIBBX30 and SIBBX31 were induced, while transcripts of $S / B B X 5, S I B B X 6, S / B B X 19$, and $S / B B X 20$ were inhibited in plants when grown at $B$ light conditions. SIBBX15 was induced by $\mathrm{G}$ light irradiation at $6 \mathrm{~h}$, whereas $S / B B X 9$ and $S / B B X 28$ were repressed (Fig. 7). Y light led to an obvious reduction in expression of $S / B B X 9$ and $S / B B X 31$. Obviously, the P light increased the expression of SIBBX3, SIBBX5, SIBBX6, SIBBX15, SIBBX19, SIBBX20, SIBBX21, $S I B B X 26$ and $S / B B X 27$, but decreased the expression of $S / B B X 10$ and $S / B B X 16$. Interestingly, SIBBX4, $S I B B X 23$ and SIBBX29 were only responsive to $\mathrm{R}$ light, while SIBBX7, SIBBX13 and SIBBX25 were induced just in response to FR light. Meanwhile, $\mathrm{R}$ light induced the expression of SIBBX14 and SIBBX24, but FR light inhibited their expression (Fig. 7). In general, the results showed that SIBBX genes might act a critical role in response to light quality signaling. 


\section{Expression pattern of the SIBBX genes in response to chilling stress}

To investigate whether $S / B B X$ genes participated in chilling stress, we analyzed the transcriptome data of tomato plants after chilling stress [43]. Results revealed that the expression levels of ten members of SIBBX family genes, including $S / B B X 3$, SIBBX16, SIBBX17, SIBBX19, SIBBX24, SIBBX26, SIBBX28, $S I B B X 29, S / B B X 30$ and $S I B B X 31$, were higher in tomato plants after chilling stress than those grown at optimal temperature conditions (Fig. 8). Furthermore, we found the transcripts of $S / B B X 1, S I B B X 7$, SIBBX9, SIBBX12, SIBBX13, SIBBX15, SIBBX18, SIBBX21, and SIBBX27 were significantly decreased after chilling stress. These findings suggest that $S / B B X$ genes might have an important role in response to chilling stress, whereas further studies are essencial to investigate the mechanism.

\section{Discussion}

Here, we identified and characterized 31 SIBBX genes in tomato (Fig. 1; Tables 1 and 2), which contained two new members (SIBBX30 and SIBBX31) in comparison with the previous studies [44]. BBX proteins are characterized by one or two B-box domains at the N-terminal and, in some cases, a CCT domain at the Cterminal [1]. Here, we found both the newly retrieved SIBBX proteins (SIBBX30 and SIBBX31) contain a Bbox domain at the N-terminal (Fig. 1 and Table 2), and they were also clustered in group V (Fig. 2). In addition, as shown in Fig. 3, the three-dimensional structures of SIBBX30 and SIBBX31 were similar to the other members of SIBBXs, which further indicated these two proteins were new SIBBX proteins. There were five subfamilies in the 32 members of Arabidopsis BBXs according to the combination of different conserved domains [2]. However, the conserved domain-based classification of tomato BBX proteins was rather complex. As shown in Fig. 2, SIBBX1-6 were classified into group I, which had two B-boxes and a CCT plus a VP domains, whereas SIBBX1 lacked a VP domain, and SIBBX2 only contained two B-boxes (Table 2). Meanwhile, SIBBX7-12 were clustered into group II, which possessed two B-boxes and a CCT domains; however, SIBBX8 and SIBBX10 had one B-box and a CCT domains, while SIBBX7 contained two B-boxes. Group V contained only one B-box, except for SIBBX27, which contained two B-boxes. We investigated the detail of sequence alignment in SIBBXs (Fig. 1), and found a high degree of conservation of the B-box1 domain among SIBBX7-12, thus the clustering results of these proteins were similar to that based on B-box1. These results indicated that during the process of evolution, some SIBBX proteins lost the B-box2 domain. Since gene duplications play a vital role in genomic rapid expansions during evolution [45], we speculated the new two genes (SIBBX30 and SIBBX31) were retrieved because of genes duplication events. The identified $S / B B X$ genes were distributed unevenly (Fig. 5a). There were no SIBBXS located in Chr11, while $S / B B X 30$ and $S / B B X 31$ were located in the Chr6 and Chr7, respectively. As shown in Fig. 5b, almost SIBBX genes were located within syntenic blocks. Among them, SIBBX30 on Chr6 and SIBBX31 on Chr7 had similarities with SIBBX28 on Chr12. These results revealed that segmental duplication events happened in the expansion of the $S I B B X$ genes family in tomato. 
Accumulating evidence showed that some BBX proteins act as central players in a variety of lightregulated physiological processes in plants. Here, we found that the number of light responsive ciselements was the largest in the promoters of 31 SIBBX genes (Fig. 6), which indicated that SIBBX genes were regulated by light signaling. Thus, we examined the gene expression of all the $S / B B X s$ in response to different light quality. Results showed that light decreased the transcripts of $S / B B X 1, S / B B X 8, S I B B X 10$ and $S / B B X 12$, while increased the transcripts of $S / B B X 7, S / B B X 13$ and $S / B B X 15$ compared with dark (Fig. 7). Previous studies had demonstrated that COP1, which is degraded after illumination, works as an E3 ubiquitin ligase that targets a variety of light signaling factors for ubiquitination and degradation in darkness $[9,46]$. For example, COP1 interacts with multiple BBXs, such as CO/BBX1 and BBX10, and subsequently degrades them by the $26 \mathrm{~S}$ proteasome system $[33,47]$. Nevertheless, COP1 stabilizes BBX11 rather than degradating it [14], which suggests that COP1 likely degrades a yet unidentified component(s) targeting BBX11. Thus, COP1 may also control the stability of SIBBX proteins, including SIBBX1, SIBBX7, SIBBX8, SIBBX10, SIBBX12, SIBBX13 and SIBBX15, in the transition from dark to light. Interestingly, we found that $S / B B X 4, S / B B X 23$ and $S / B B X 29$ were only in response to R light, while $S / B B X 7$, $S I B B X 13$ and $S I B B X 25$ were just in response to FR light (Fig. 7). These results indicated that these SIBBX proteins might directly interact with the photoreceptors, which sense R and FR light signals. Similarly, recent work has revealed that phyB directly interacts with BBX4 and positively regulates its accumulation in red light in Arabidopsis [25], which demonstrates that photoreceptors may directly control some BBX proteins. In addition, the results showed that R light induced the expression of SIBBX14 and SIBBX24, whereas FR light inhibited their expression (Fig. 7), which implied that these two SIBBX proteins might function antagonistically to regulate some plant physiological processes, such as shade avoidance and the elongated of hypocotyls. Here, we observed that B light induced the gene expression of $S I B B X 16$, $S I B B X 17, S / B B X 18, S / B B X 30$ and $S / B B X 31$, whereas inhibited the transcripts of $S / B B X 5, S / B B X 6, S I B B X 19$ and $S / B B X 20$ (Fig. 7). Previous work demonstrated that $B B X 28 / B B X 29$ and BBX30/BBX31 could precisely control each other by forming a feedback loop in Arabidopsis [19, 20, 22, 23]. Thus, these SIBBX proteins may work in concert with each other and some unidentified factors to regulate the plant growth in response to light signaling.

Light and temperature are more or less inter-related during plant growth and stress response [48]. Studies previously showed that BBX18 and BBX23 are involved in the thermomorphogenesis in Arabidopsis [38]. Both $M d B B X 20$ and $M a C O L 1$ are responsive to low temperatures in apple and banana, respectively [39, 40]. ZFPL, a homologous gene of $A t B B X 32$, enhances cold tolerance in grapevine [41]. Furthermore, CmBBX24 also increases plant cold tolerance in Chrysanthemum [42]. However, whether SIBBXs regulate plant cold response in tomato remains elusive. Here, we observed that there were numerous hormones and stress responsive cis-elements in the promoters of $S I B B X$ genes (Fig. 7). Furthermore, the results showed that low temperatures induced the expression of $S I B B X 3$, SIBBX16, SIBBX17, SIBBX19, SIBBX24, SIBBX26, SIBBX28, SIBBX29, SIBBX30 and SIBBX31, whereas inhibited the transcripts of SIBBX1, SIBBX7, $S I B B X 9, S I B B X 12, S I B B X 13, S I B B X 15, S I B B X 18, S I B B X 21$ and SIBBX27 (Fig. 8). We have demonstrated that SIHY5 positively regulates plant cold tolerance $[49,50]$, and a variety of BBX proteins interact with HY5 [19, 20, 22, 23]; thus, it indicates that SIBBXs may play critical roles in plant cold tolerance in tomato. 


\section{Conclusions}

In conclusion, this investigation found two new members (SIBBX30 and SIBBX31) of the SIBBX gene family. We made a systematic analysis of the 31 SIBBX genes, including their conserved domain, phylogenetic relationship, three-dimensional structure, gene structure, chromosome location, gene duplication and cis-elements analysis. The results suggested that 31 members of SIBBXs were distributed unevenly in the whole genome, and no SIBBXS were located on chromosome 11. Gene duplication analysis indicated that segmental duplications had driven the expansion of the tomato $B B X$ genes. Gene expression analysis revealed that multiple $S I B B X$ genes highly responsive to light quality and low temperatures, which lay a foundation for understanding their biological functions in response to the crosstalk between light and temperature.

\section{Methods}

\section{Plant material and growth conditions}

Seeds of wild-type tomato (Solanum lycopersicum) in the cv 'Ailsa Craig' (Accession: LA2838A) background were obtained from the Tomato Genetics Resource Center (http: //tgrc.ucdavis.edu) as previously reported [48]. Seedlings, which grown in pots with a mixture of one part vermiculite to three parts peat, receive Hoagland nutrient solution. The growth conditions for tomato seedlings were 25/20 ${ }^{\circ} \mathrm{C}$ (day/night) temperature with a $12 \mathrm{~h}$ photoperiod, the light intensity of $600 \mu \mathrm{mol} \mathrm{m} \mathrm{m}^{-2} \mathrm{~s}^{-1}$, and $65 \%$ relative humidity.

\section{Light and cold treatments}

The six-leaf stage plants were used for all experiments. Plants were grown at white light conditions with an aerial temperature of $25^{\circ} \mathrm{C}$ or $4^{\circ} \mathrm{C}$ for the cold treatment in controlled environment growth chambers (Ningbo Jiangnan instrument factory, Ningbo, China). For light quality treatments, plants were exposed to dark (D), white light (W) or different wavelength [purple (P), $394 \mathrm{~nm}$; blue (B), $450 \mathrm{~nm}$; green (G), $522 \mathrm{~nm}$; yellow (Y), $594 \mathrm{~nm}$; red (R), $660 \mathrm{~nm}$ and far-red (FR), $735 \mathrm{~nm}$, Philips] light from 6:00 AM to 6:00 PM. The light intensity was $100 \mu \mathrm{mol} \mathrm{m} \mathrm{m}^{-2} \mathrm{~s}^{-1}$. The Lighting Passport (Asensetek, Model No. ALP-01, Taiwan) was used to measure light intensity and light quality as a previous study [51].

\section{Genome-wide identification of SIBBX genes in tomato}

The protein sequence of Arabidopsis BBXs were downloaded from the TAIR database (https:// www.arabidopsis.org/). Tomato BBX proteins were searched and downloaded from three public databases, including the NCBI database (http:// www.ncbi.nlm.nih.gov/), the Phytozome 11.0 database (https://phytozome.jgi.doe.gov/pz/portal.html) and the Sol Genomics Network tomato database (https://solgenomics.net/). We chose the candidate $B B X$ accroding to the E-value $\left(1 \mathrm{e}^{-5}\right)$ and the highest 
similarity scores. All the putative $B B X$ genes were submitting to the InterProScan database (http://www.ebi.ac.uk/interpro/), SMART (http://smart.embl-heidelberg.de/) and Conserved Domains Database (http://www.ncbi.nlm.nih.gov/cdd/) to further confirm their completeness and existence of the core domains. The proteins without the B-Box domain and duplicate proteins were removed.

\section{Protein properties, multiple sequence alignment and phylogenetic analysis}

The various physiochemical properties of tomato BBX proteins, such as MW, polypeptide length, pl, instability index, aliphatic index and GRAVY were investigated using the ExPASy online tool (http://web.expasy.org/protparam/). To estimate the subcellular localization of tomato BBX proteins, we used CELLO v.2.5: sub-cellular localization predictor (http://cello.life.nctu.edu.tw/) [52] and pSORT prediction software (http://www.genscript.com/wolf-psort.html) [53]. ORF numbers were calculated using the NCBI website (https://www.ncbi.nlm.nih.gov/orffinder/).

Multiple sequence alignments of all BBX proteins, including 31 SIBBX and 32 AtBBX proteins, were performed with the MUSCLE (https://www.ebi.ac.uk/Tools/msa/muscle/) [54] and DNAMAN software (Version 5.2.2). We constructed a neighbor-joining phylogenetic tree using MEGA 7.0 with 1000 bootstrap value and Jones-Taylor-Thornton ( $\mathrm{G}$ ) method [55], and embellish the phylogenetic tree with an online website Evolview (http://www.evolgenius.info/evolview/\#mytrees/)[56].

\section{Conserved motifs analysis and three-dimensional structure prediction}

The presence of conserved BBX_N and CCT_C - domains were identified by NCBI (https://www.ncbi.nlm.nih.gov/Structure/cdd/wrpsb.cgi), and drawn with IBS software (Illustrator for Biological Sequences, http://ibs.biocuckoo.org/online.php) [57]. We identified the conserved motifs using the Meme program (http://meme-suite.org/index.html) [58], which was run with the maximum number of motifs that were defined as 10 , the maximum width was set to 300 , and the e-values $<1 e^{-30}$. The threedimensional structure of tomato $B B X$ proteins were generated with a 3D-PSSM online website (http://www.sbg.bio.ic.ac.uk/ phyre2/html/page.cgi?id=index).

\section{Chromosomal location, gene structure, tandem duplication and synteny analysis}

SIBBX genes were mapped to tomato chromosomes according to the Phytozome 11.0 database with the MapChart software. The chromosome distribution diagram was drawn by the online website MG2C 
(http://mg2c.iask.in/mg2c_v2.1/) with the information from Sol Genomics Network (http://www.solgenomics.net).

Exon and intron structures of the SIBBXs were determined accroding to their corresponding full-length gene sequences in Phytozome11.0 database. We performed gene structure analysis of the SIBBX genes by using the gene structure display server (GSDS, http://gsds.cbi.pku.edu.cn/) [59].

The syntenic blocks were designed from the Plant Genome Duplication Database (http://chibba.agtec.uga.edu/duplication/). MCscanX (http://chibba.pgml.uga.edu/mcscan2/) was used to investigate duplication types and gene syntenic [60]. The synteny figures were drawn by Circos-0.69 (http://circos.ca/) with E-value setting to $1 \mathrm{e}^{-10}$ and output format as tabular (-m 8). We used the physical location of a gene on the chromosome to find out the tandem duplication of SIBBX genes in tomato.

\section{Cis-elements of promoters analysis}

To identify potential light-, stress-, hormone- and development-related cis-elements, the 2000-bp genomic DNA sequence upstream of the start codon (ATG) of SIBBX genes were obtained from the tomato genome database. The cis-elements in these SIBBX genes promoter were identified by using the Plant CisActing Regulatory Element (PlantCARE; http://bioinformatics.psb.ugent.be/webtools/plantcare/html/) [61].

\section{Gene expression analysis}

Total RNA was extracted from tomato leaves as previously $[62,63]$. RNA-seq data of the tomato plants after exposure to $25^{\circ} \mathrm{C}$ or $4^{\circ} \mathrm{C}$ for $6 \mathrm{~h}$ were obtained and performed as described previously [43, 49]. Three biological replicates for various samples were prepared. For the gene transcript analysis, the cDNA template for real-time RT-PCR was synthesized using a Rever-Tra Ace qPCR RT Kit with a genomic DNAremoving enzyme (Toyobo). qRT-PCR experiments were carried out with an SYBR Green PCR Master Mix Kit (TaKaRa) using an Applied Biosystems 7500 Real-Time PCR System (qTOWER ${ }^{3}$ G, Germany). The PCR was run at $95^{\circ} \mathrm{C}$ for $3 \mathrm{~min}$, followed by 40 cycles of $30 \mathrm{~s}$ at $95^{\circ} \mathrm{C}, 30 \mathrm{~s}$ at $58^{\circ} \mathrm{C}$, and $1 \mathrm{~min}$ at $72^{\circ} \mathrm{C}$. The Tomato ACTIN2 gene was used as an internal control to normalize small differences in template amounts. The relative gene expression was calculated as described previously [64]. The primers sequence was in Additional file 2: Table S2.

\section{Abbreviations}

BBXs: B-box proteins; COP1: Constitutively photomorphogenic 1; HY5: Elongated hypocotyl 5; VP: Valineproline; ZFPL: Zinc-finger protein like; CCT: Constans , CO-like, and Timing of CAB; CDS: Coding sequence; pl: Theoretical isoelectric point; AA: Amino acids; Chr: Chromosome; Gravy: Grand average of hydropathicity; MW: Molecular weight; qRT-PCR: Real-Time PCR; TFs: Transcription factors. 


\section{Declarations}

\section{Acknowledgements}

We are grateful to the Tomato Genetics Resource Center at the California University for tomato seeds.

\section{Authors' contributions}

FW and TLL designed the research, FW, XB, XJW, JRY, YZ, SYZ and XS performed the experiments. FW, YFL,TX, HYQ, MFQ, YXY and GJA analyzed the data. FW, GJA and TLL wrote and revised the paper. All authors have read and approved the manuscript.

\section{Funding}

This research was supported by the National Natural Science Foundation of China (31801904), the Liao Ning Revitalization Talents Program (XLYC1807020), the Doctoral Start-up Foundation of Liaoning Province (20180540094), the National Key Research and Development Program of China (2018YFD1000800; 2019YFD1000300), the Innovative Talent Support Program for the Universities in Liaoning Province, the Young and Middle-aged Science and Technology Innovation Talent Support Program in Shenyang (RC200449), and the Start-up Foundation of Shenyang Agricultural University. The funders supported this research project but played no role in the design of the study and collection, analysis, and interpretation of data and in writing the manuscript.

\section{Availability of data and materials}

The RNA-seq datasets for expression profiles used in this study were downloaded from NCBI (https://pubmed.ncbi.nlm.nih.gov/31189657/). The datasets are available in the published article Additional file (Supplemental Tables S2 to S4) [43].

\section{Ethics approval and consent to participate}

Not applicable.

\section{Consent for publication}

Not applicable.

\section{Competing interests}


The authors declare that they have no competing interests.

\section{Author details}

${ }^{1}$ College of Horticulture, Shenyang Agricultural University, Shenyang, 110866, P.R. China.

${ }^{2}$ Key Laboratory of Protected Horticulture, Ministry of Education, Shenyang, 110866, P.R. China.

${ }^{3}$ National \& Local Joint Engineering Research Center of Northern Horticultural Facilities Design \& Application Technology (Liaoning), Shenyang, 110866, P.R. China.

${ }^{4}$ College of Land and Environment, Shenyang Agricultural University, Shenyang, 110866, P.R. China.

${ }^{5}$ College of Agronomy, Jiangxi Agricultural University, Nanchang, 330045, P.R. China. ${ }^{6}$ College of Forestry, Henan University of Science and Technology, Luoyang, 471000, P.R. China

\section{References}

1. Gangappa SN, Botto JF. The BBX family of plant transcription factors. Trends Plant Sci. 2014;19(7):460-470.

2. Khanna R, Kronmiller B, Maszle DR, Coupland G, Holm M, Mizuno T, Wu SH. The Arabidopsis B-box zinc finger family. Plant Cell. 2009;21(11):3416-3420.

3. Crocco CD, Botto JF. BBX proteins in green plants: Insights into their evolution, structure, feature and functional diversification. Gene. 2013;531(1):44-52.

4. Gendron JM, Pruneda-Paz JL, Doherty CJ, Gross AM, Kang SE, Kay SA. Arabidopsis circadian clock protein, TOC1, is a DNA-binding transcription factor. Proc Natl Acad Sci. 2012;109(8):3167-3172.

5. Datta S, Hettiarachchi GHCM, Deng XW, Holm M. Arabidopsis CONSTANS-LIKE3 is a positive regulator of red light signaling and root growth. Plant Cell. 2006;18(1):70-84.

6. Holm M, Hardtke CS, Gaudet R, Deng XW. Identification of a structural motif that confers specific interaction with the WD40 repeat domain of Arabidopsis Embo Journal. 2001;20(1):118-127.

7. Galvao VC, Fankhauser C. Sensing the light environment in plants: photoreceptors and early signaling steps. Curr Opin Neurobiol. 2015;34C:46-53.

8. Paik I, Huq E. Plant photoreceptors: Multi-functional sensory proteins and their signaling networks. Semin Cell Dev Biol. 2019;92:114-121.

9. Osterlund MT, Hardtke CS, Wei N, Deng XW. Targeted destabilization of HY5 during light-regulated development of Arabidopsis. Nature. 2000;405(6785):462-466.

10. Ahammed GJ, Gantait S, Mitra M, Yang Y, Li X. Role of ethylene crosstalk in seed germination and early seedling development: A review. Plant Physiology and Biochemistry. 2020; doi:10.1016/j.plaphy.2020.03.016. 
11. Xu DQ, Jiang Y, Li JG, Lin F, Holm M, Deng XW. BBX21, an Arabidopsis B-box protein, directly activates HY 5 and is targeted by COP1 for $26 \mathrm{~S}$ proteasome mediated degradation. Proc Natl Acad Sci. 2016;113(27):7655-7660.

12. Xu DQ, Jiang Y, Li J, Holm M, Deng XW. The B-Box domain protein BBX21 promotes photomorphogenesis. Plant Physiol. 2018;176(3):2365-2375.

13. Xu DQ. COP1 and BBXs-HY5-mediated light signal transduction in plants. New Phytol; 2019. https:// doi:1111/nph.16296

14. Zhao XH, Heng YQ, Wang XC, Deng X, Xu DQ. A positive feedback loop of BBX11-BBX21-HY5 promotes photomorphogenic development in Arabidopsis. Plant Commun. 2020. https://doi.org/10.1016/j.xplc.2020.100045

15. Datta S, Johansson H, Hettiarachchi C, Irigoyen ML, Desai M, Rubio V, Holm M. LZF1/SALT TOLERANCE HOMOLOG3, an Arabidopsis B-box protein involved in light-dependent development and gene expression, undergoes COP1-mediated ubiquitination. Plant Cell. 2008;20(9):2324-2338.

16. Zhang XY, Huai JL, Shang FF, Xu G, Tang WJ, Jing YJ, Lin RC. A PIF1/PIF3-HY5-BBX23 transcription factor cascade affects photomorphogenesis. Plant Physiol. 2017;174(4): 2487-

17. Job N, Yadukrishnan P, Bursch K, Datta S, Johansson H. Two B-Box proteins regulate photomorphogenesis by oppositely modulating HY5 through their diverse C-terminal domains. Plant Physiol. 2018;176(4):2963-2976.

18. Gangappa SN, Crocco CD, Johansson H, Datta S, Hettiarachchi C, Holm M, Botto JF. The Arabidopsis B-box protein BBX25 interacts with HY5, negatively regulating BBX22 expression to suppress seedling photomorphogenesis. Plant Cell. 2013;25(4):1243-1257.

19. Lin F, Jiang Y, Li J, Yan TT, Fan LM, Liang JS, Chen ZJ, Xu DQ, Deng XW. B-BOX DOMAIN PROTEIN28 negatively regulates photomorphogenesis by repressing the activity of transcription factor HY 5 and undergoes COP1-mediated degradation. Plant Cell. 2018;30(9):2006-

20. Song ZQ, Yan TT, Liu JJ, Bian YT, Heng YQ, Lin F, Jiang Y, Deng XW, Xu DQ. BBX28/BBX29-HY5BBX30/31 form a feedback loop to fine-tune photomorphogenic development. Plant J. 2020. https://doi.org/10.1111/tpj.14929

21. Chang CSJ, Li YH, Chen LT, Chen WC, Hsieh WP, Shin J, Jane WN, Chou SJ, Choi G, Hu JM, Somerville $\mathrm{S}$, Wu SH. LZF1, a HY5-regulated transcriptional factor, functions in Arabidopsis de-etiolation. Plant J. 2008;54(2):205-219.

22. Heng YQ, Lin F, Jiang Y, Ding MQ, Yan TT, Lan HX, Zhou H, Zhao XH, Xu DQ, Deng XW. B-Box containing proteins $B B X 30$ and $B B X 31$, acting downstream of $H Y 5$, negatively regulate photomorphogenesis in Arabidopsis. Plant Physiol. 2019a;180(1):497-

23. Yadav A, Bakshi S, Yadukrishnan P, Lingwan M, Dolde U, Wenkel S, Masakapalli SK, Datta S. The BBox-containing microprotein miP1a/BBX31 regulates photomorphogenesis and UV-B protection. Plant Physiol. 2019;179(4):1876-

24. Holtan HE, Bandong S, Marion CM, Adam L, Tiwari S, Shen Y, Maloof JN, Maszle DR, Ohto MA, Preuss S, Meister R, Petracek M, Repetti PP, Reuber TL, Ratcliffe OJ, Khanna R. BBX32, an 
Arabidopsis B-Box protein, functions in light signaling by suppressing HY5-regulated gene expression and interacting with STH2/BBX21. Plant Physiol. 2011;156(4):2109-2123.

25. Heng YQ, Jiang Y, Zhao XH, Zhou H, Wang XC, Deng XW, Xu DQ. BBX4, a phyB-interacting and modulated regulator, directly interacts with PIF3 to fine tune red light-mediated photomorphogenesis. Proc Natl Acad Sci. 2019b;116(51):26049-26056.

26. Bai B, Lu NN, Li YP, Guo SL, Yin HB, He YN, Sun W, Li W, Xie XZ. OsBBX14 promotes photomorphogenesis in rice by activating OsHY5L1 expression under blue light conditions. Plant Sci. 2019a;284:192-202.

27. An JP, Wang XF, Espley RV, Wang KL, Bi SQ, You CX, Hao YJ. An apple b-box protein MdBBX37 modulates anthocyanin biosynthesis and hypocotyl elongation synergistically with MdMYBs and MdHY5. Plant Cell Physiol. 2019a;61(1):130-143.

28. An JP, Wang XF, Zhang XW, Bi SQ, You CX, Hao YJ. MdBBX22 regulates UV-B-induced anthocyanin biosynthesis through regulating the function of MdHY5 and is targeted by MdBT2 for 26S proteasome-mediated degradation. Plant Biotechnol J. 2019b;17(12): 2231-2233.

29. Bai SL, Tao RY, Tang YX, Yin L, Ma YJ, Ni JB, Yan XH, Yang QS, Wu ZY, Zeng YL, Teng YW. BBX16, a B-box protein, positively regulates light-induced anthocyanin accumulation by activating MYB10 in red pear. Plant Biotechnol J. 2019b;17(10):1985-1997.

30. Bai SL, Tao RY, Yin L, Ni JB, Yang QS, Yan XH, Yang F, Guo XP, Li HX, Teng YW. Two B-box proteins, PpBBX18 and PpBBX21, antagonistically regulate anthocyanin biosynthesis via competitive association with Pyrus pyrifolia ELONGATED HYPOCOTYL 5 in the peel of pear fruit. Plant J. 2019c;100(6):1208-1223.

31. Fan XY, Dong YS, Cao DM, Bai MY, Luo XM, Yang HJ, Wei CQ, Zhu SW, Sun Y, Chong K, Wang ZY. BZS1, a B-box protein, promotes photomorphogenesis downstream of both brassinosteroid and light signaling pathways. Mol Plant. 2012;5(3):591-600.

32. Wang CQ, Sarmast MK, Jiang J, Dehesh K. The transcriptional regulator BBX19 promotes hypocotyl growth by facilitating COP1-Mediated EARLY FLOWERING3 degradation in Arabidopsis. Plant Cell. 2015; 27(4):1128-1139.

33. Ordoñez-Herrera N, Trimborn L, Menje M, Henschel M, Robers L, Kaufholdt D, Hänsch R, Adrian J, Ponnu J, Hoecker U. The transcription factor COL12 is a substrate of the COP1/SPA E3ligase and regulates flowering time and plant architecture. Plant Physiol. 2018;176(2):1327-1340.

34. Nagaoka S, Takano T. Salt tolerance-related protein STO binds to a Myb transcription factor homologue and confers salt tolerance in Arabidopsis. J. Exp. Bot. 2003;54(391):2231-2237.

35. Min JH, Chung JS, Lee KH, Kim CS. The CONSTANS-like 4 transcription factor, AtCOL4, positively regulates abiotic stress tolerance through an abscisic acid-dependent manner in Arabidopsis. $J$ Integr Plant Bio. 2015;57(3):313-324.

36. Liu YN, Chen H, Ping Q, Zhang ZX, Guan ZY, Fang WM, Chen SM, Chen FD, Jiang JF, Zhang F. The heterologous expression of $\mathrm{CmBBX} 22$ delays leaf senescence and improves drought tolerance in Arabidopsis. Plant Cell Rep. 2019a;38(1):15-24. 
37. Liu X, Li R, Dai Y, Yuan L, Sun QH, Zhang SZ, Wang X. A B-box zinc finger protein, MdBBX10, enhanced salt and drought stresses tolerance in Arabidopsis. Plant Mol Biol. 2019b;99(4-5):437-

38. Ding L, Wang S, Song ZT, Jiang YP, Han JJ, Lu SJ, Li L, Liu JX. Two B-Box domain proteins, BBX18 and BBX23, interact with ELF3 and regulate thermomorphogenesis in Arabidopsis. Cell Rep. 2018;25(7):1718-

39. Chen J, Chen JY, Wang JN, Kuang JF, Shan W, Lu WJ. Molecular characterization and expression profiles of MaCOL1, a CONSTANS-like gene in banana fruit. Gene. 2012;496(2):110-117.

40. Fang HC, Dong YH, Yue XX, Hu JF, Jiang SH, Xu HF, Wang YC, Su MY, Zhang J, Zhang ZY, Wang N, Chen XC. The B-Box zinc finger protein MdBBX20 integrates anthocyanin accumulation in response to ultraviolet radiation and low temperature. Plant Cell Environ. 2019a;42(7):2090-2104.

41. Takuhara Y, Kobayashi M, Suzuki S. Low-temperature induced transcription factors in grapevine enhance cold tolerance in transgenic Arabidopsis plants. J Plant Physiol. 2011;168(9):967-975.

42. Yang YJ, Ma C, Xu YJ, Wei Q, Imtiaz M, Lan HB, Gao S, Cheng LN, Wang MY, Fei ZJ, Hong B, Gao JP. A zinc finger protein regulates flowering time and abiotic stress tolerance in Chrysanthemum by modulating gibberellin biosynthesis. Plant Cell. 2014;26(5):2038-2054.

43. Fang PP, Yan MY, Chi C, Wang MQ, Zhou YH, Zhou J, Shi K, Xia XJ, Foryer CH, Yu JQ. Brassinosteroids act as a positive regulator of photoprotection in response to chilling stress. Plant Physiol. 2019b;180(4):2061-2076.

44. Chu ZN, Wang X, Li Y, Yu HY, Li JH, Lu YE, Li HX, Ouyang B. Genomic organization, phylogenetic and expression analysis of the B-BOX gene family in tomato. Front. Plant Sci. 2016;7:1552.

45. Vision TJ, Brown DG, Tanksley SD. The origins of genomic duplications in Arabidopsis. Science. 2000;290(5499):2114-2117.

46. Han X, Huang X, Deng XW. The photomorphogenic central repressor COP1: conservation and functional diversification during evolution. Plant Commun. 2020;1(3):2590-3462.

47. Liu LJ, Zhang YC, Li QH, Sang Y, Mao J, Lian HL, Wang L, Yang HQ. COP1-mediated ubiquitination of CONSTANS is implicated in cryptochrome regulation of flowering in Arabidopsis. Plant Cell. 2008;20(2):292-306.

48. Wang F, Guo ZX, Li HZ, Wang MM, Onac E, Zhou J, Xia XJ, Shi K, Yu JQ, Zhou YH. Phytochrome A and $B$ function antagonistically to regulate cold tolerance via abscisic acid-dependent jasmonate signaling. Plant Physiol. 2016; 170(2): 459-471.

49. Wang F, Wu N, Zhang LY, Ahammed GL, Chen XX, Xiang X, Zhou J, Xia XJ, Shi K, Yu JQ, Foyer CH, Zhou $\mathrm{YH}$. Light signaling-dependent regulation of photoinhibition and photoprotection in tomato. Plant Physiol. 2018;176(2):1311-1326.

50. Wang F, Zhang LY, Chen XX, Wu XD, Xiang X, Zhou J, Xia XJ, Shi K, Yu JQ, Foyer CH, Zhou YH. SIHY5 integrates temperature, light and hormone signaling to balance plant growth and cold tolerance. Plant Physiol. 2019;179(2):749-760.

51. Wang F, Yan JR, Ahammed GJ, Wang XJ, Bu X, Xiang HZ, Li YB, Lu JZ, Liu YF, Qi HY, Qi MF and Li TL. PGR5/PGRL1 and NDH mediate far-red light-induced photoprotection in response to chilling stress in 
tomato. Plant Sci. 2020a;11:669.

52. Yu CS, Chen YC, Lu CH, Hwang JK. Prediction of protein subcellular localization.

Proteins. 2006;64(3):643-651.

53. Horton P, Park KJ, Obayashi T, Fujita N, Harada H, Adams-Collier CJ, Nakai K. WoLF PSORT: protein localization predictor. Nucleic Acids Res. 2007;35:W585-W587.

54. Edgar RC. MUSCLE: multiple sequence alignment with high accuracy and high throughput. Nucleic Acids Res. 2004;32(5):1792-1797.

55. Kumar S, Stecher G, Tamura K. MEGA7: molecular evolutionary genetics analysis version 7.0 for bigger datasets. Mol Biol Evol. 2016;33(7):1870-1874.

56. Zhang HK, Gao SH, Lercher MJ, Hu SN, Chen WH. EvolView, an online tool for visualizing, annotating and managing phylogenetic trees. Nucleic Acids Res. 2012;40: W569-W572.

57. Ren J, Wen LP, Gao XJ, Jin CJ, Xue Y, Yao XB. DOG 1.0: illustrator of protein domain structures. Cell Res. 2009;19(2):271-2733.

58. Bailey TL, Boden M, Buske FA, Frith M, Grant CE, Clementi L, Ren JY, Li WW, Noble WS MEME SUITE: tools for motif discovery and searching. Nucleic Acids Res. 2009;37(2):W202-208.

59. Hu B, Jin JP, Guo AY, Zhang H, Luo JC, Gao G. GSDS 2.0: an upgraded gene feature visualization server. Bioinformatics. 2015;31(8):1296-1297.

60. Wang YP, Tang HB, Debarry JD, Tan X, Li JP, Wang XY, Lee Tae-ho, Jin HZ, Marler B, Guo H, Kissinger JC, Paterson AH. MCScanX: a toolkit for detection and evolutionary analysis of gene synteny and collinearity. Nucleic Acids Res. 2012;40(7):e49.

61. Lescot $M$, Déhais $P$, Thijs $G$, Marchal $K$, Moreau $Y$, Van de Peer $Y$, Rouzé P, Rombauts S. PlantCARE, a database of plant cis-acting regulatory elements and a portal to tools for in silico analysis of promoter sequences. Nucleic Acids Res. 2002;30(1):325-327.

62. Wang F, Chen XX, Dong SJ, Jiang XC, Wang LY, Yu JQ, Zhou YH. Crosstalk of PIF4 and DELLA modulates CBF transcript and hormone homeostasis in cold response in tomato. Plant Biotechnol. J. 2020b;18(4):1041-1055.

63. Ahammed GJ, Li X, Yang YX, Liu CC, Cheng Y. Tomato WRKY81 acts as a negative regulator for drought tolerance by modulating guard cell $\mathrm{H}_{2} \mathrm{O}_{2}$-mediated stomatal closure. Environ Exp Bot. 2019; 171: 103960.

64. Livak KJ, Schmittgen TD. Analysis of relative gene expression data using real-time quantitative PCR and the $2^{-\triangle \Delta C T}$ Methods. 2001;25(4):402-408.

\section{Tables}

Due to technical limitations, tables are only available as a download in the Supplemental Files section.

\section{Figures}


A

B-BOX1 domain

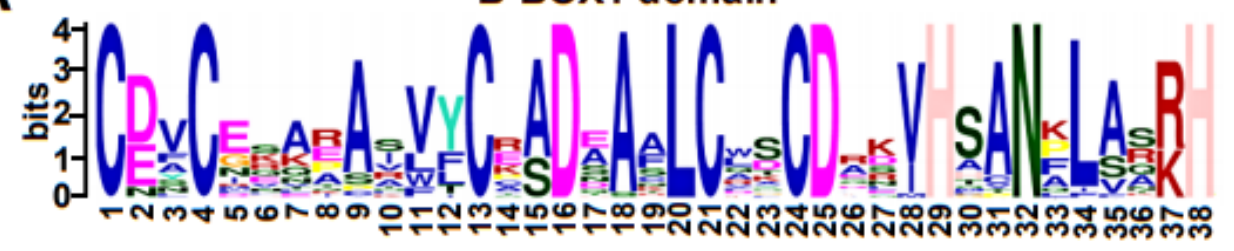

B-BOX2 domain

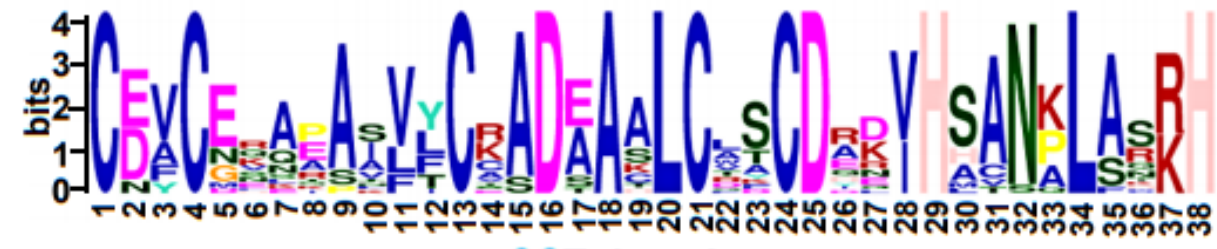

CCT domain

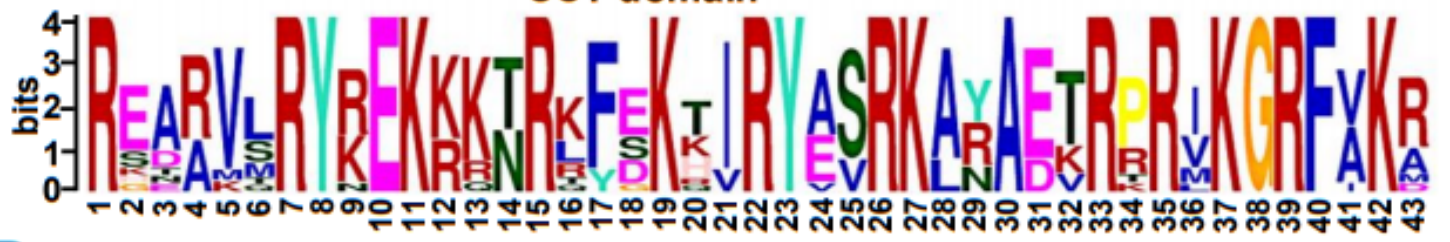

B

SIBBX1

SIBBX3

SIBBX2

SIBBX4

SIBBX5
SIBBX6

SIBBX18

SIBBX19

SIBBX20

SIBBX2

SIBBX25

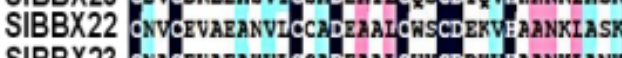

SIBBX GaCEVAzaKVi CCaDEaAI GY CDDKVHAaNKIANKE 42

SIBBX24 ODVOEKAC्AATVICCADEAAICAKCDIIVHAANKIASKE 42

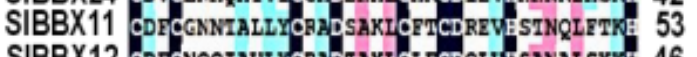

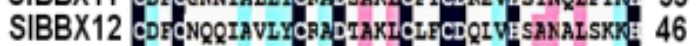

SIBBX8 QERGGEQRSIVYORSDAACIOLSCDENVHSANALSQRE 39

SIBBX9 OEYGGEQRSIVYORSDSACI OLSCDFNIE SANAISQRE 42

SIBBX7 DEYCGEQRSIVYORSDAACIOLSCDENVESANAL SQRE 42

SIBBX10 dDICGEVRAVVYCKSDSARI ILCCDDYVESENLISREE 42

SIBBX27 dERGMLLKFVVY CEADAAHIOLSCDAKVHSANALSNEE 44

SIBBX 13 dDNCIRKRABWY AADDCAFICQSCESSVESANPIARBE 56

SIBBX15 dONCIKKRABWY EFADCAFICCN CDASVESANPIARRE 57

SIBBX 14 CDSOLSKRABWE dEADCAFICOSCLVSIHSANQIASRE: 57

SIBBX 16 dEIOK. SEAYVY OEAONAFI OKKCDKIVHTANFIAQPE 58

SIBBX 17 dAICS. SEASVYCZADNAFI CRKCDRSVEGANFIAQRE 71

SIBBX28 dEI ON. GLARIYOESDHANI OND CDLKVESANFIVAKE 40

SIBBX30 dEICN. GLABMYOESDNASI ONDCDAKVHSANFIAARE 40

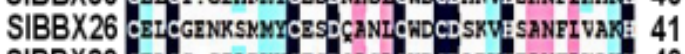

SIBBX29 dEI SS. SIABVY CESDC CASI CND CDABVETANFIVAKE 40

SIBBX31 dEI GN. DC CAALEGPSDSAFI GFICLAKVECANFIVARE 45
B-BOX2 domain

SIBBX1 OEACERAFAAFI CKACAA SICASCEADIESANPL.AHRH 101 SIBBX3 dEA GERAFAarI CKACAA SIOASCEADIH SANPL.ARRH 94

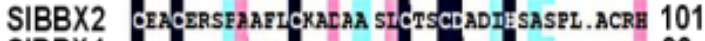

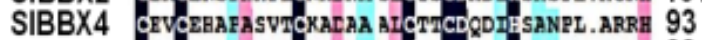
SIBBX5 OEVOECCAFASVI GKALAA AI GVICDRDIHSANPL. ARRB 93 SIBBX6 OEVOEÇAAASVI GRACAA AI GVZ CDRDIISSANPL. ARRH 101

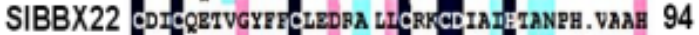
SIBBX 23 DDICQETVGFF BLLEDBA LICRKCDISIHTVNAY.VSSH 94 SIBBX24 CDICQDKAAFIFCVEDBA LFCKDCDEAIHSASSL . AKNH 94 SIBBX20 CDICQRRRGFLFCQQDAA IM CRECDIPIHKANBH. TQKH 95 SIBBX21 CDICQERBAFLECQQDBA II CRECLVSIEKANBH . TQKB 95 SIBBX25 CDICQBRAALLFOKZDFA II CKECDLPIHKANEH. TKKK 95

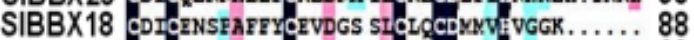
SIBBX 19 DDIOENAFAFIYOEIDGS SIOI CCDMIVHVGGKR . THGR 93

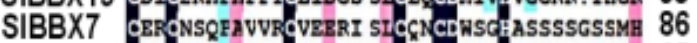

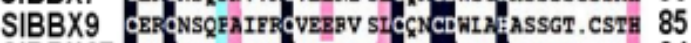
SIBBX 27 OECGGENFAYIRCSDHQT EMdRDCDRCBHDLSSQ.... 84 SIBBX 11 ONICDSSPASII CCTËTS VICCR CDNESHN. . KLLS. LH 94 SIBBX 12 GDNGGSEFVSIRCDTDKL VICEDCLNCRHGSCAVSG.AB 89

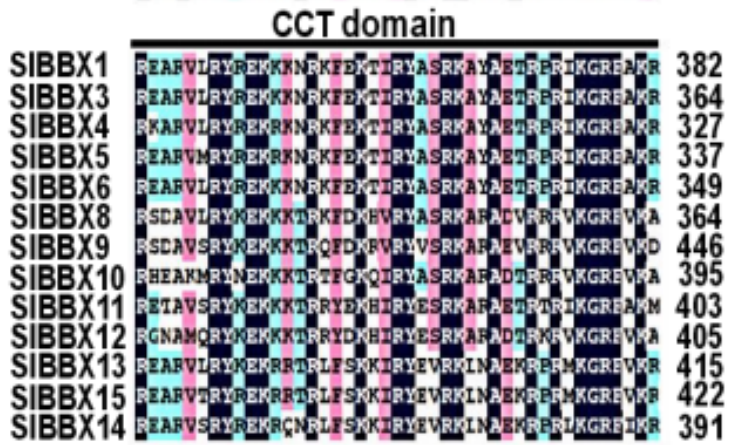

\section{Figure 1}

Domain composition of SIBBX proteins. a The amino acid sequence alignment of the B-box1, B-box2 and CCT domain. The $y$-axis and $x$-axis indicated the conservation rate of each amino acid and the conserved sequences of the domain, respectively. $b$ Multiple sequence alignments of the domains of the SIBBXs. Multiple sequence alignments of the B-box1, B-box2 and CCT domains are shown. The identical conserved amino acids were represented by black and pink shaded. 


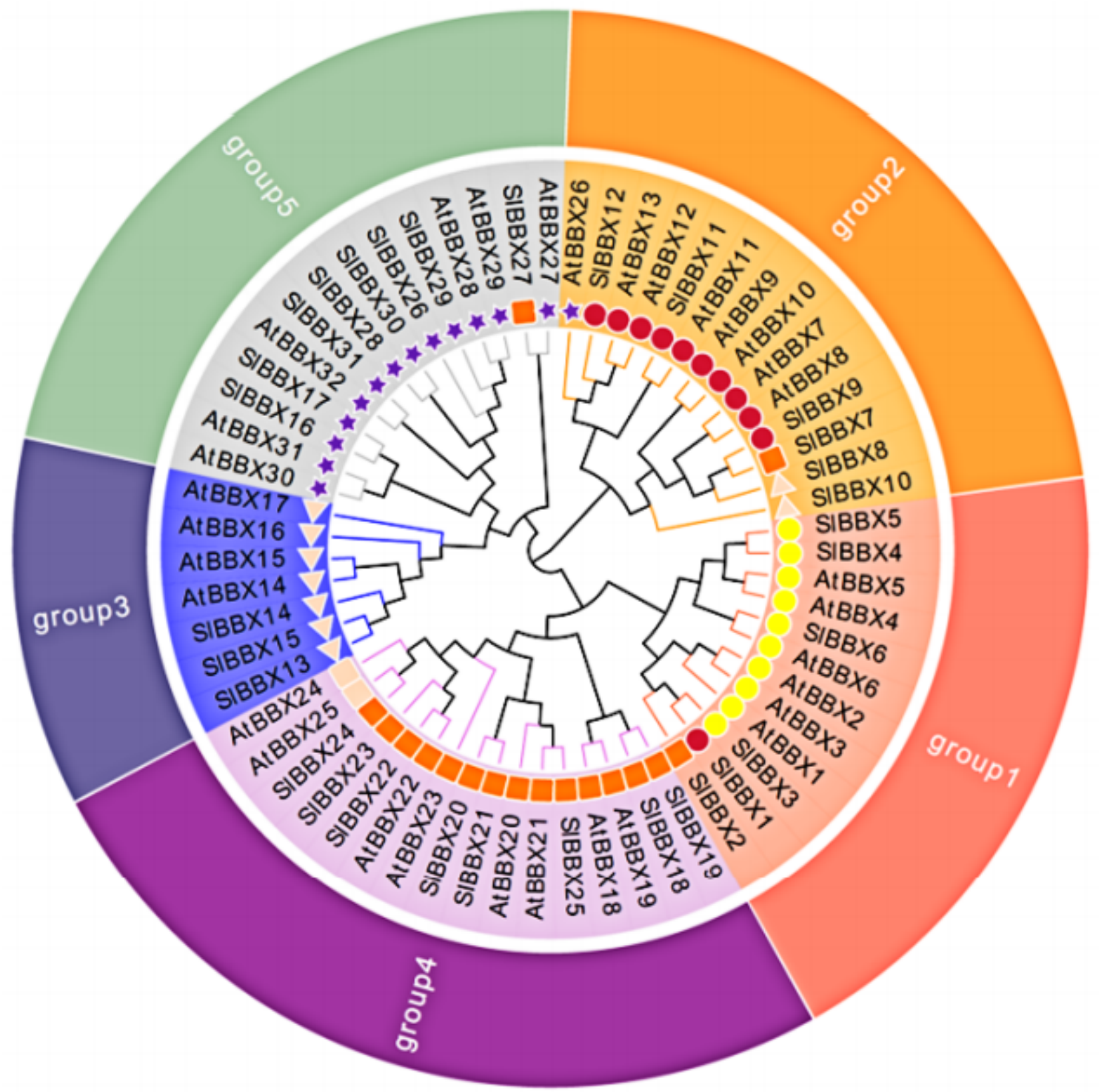

Figure 2

Phylogenetic analysis of SIBBX genes in tomato. All SIBBX proteins were divided into five subclasses represented by different colored clusters. Red, orange, bule, purple, and green clusters represent subclasses I, II, III, IV and V, respectively. The phylogenetic tree was constructed by the neighbor-joining method using MEGA7 software with 1000 bootstrap replicates. 

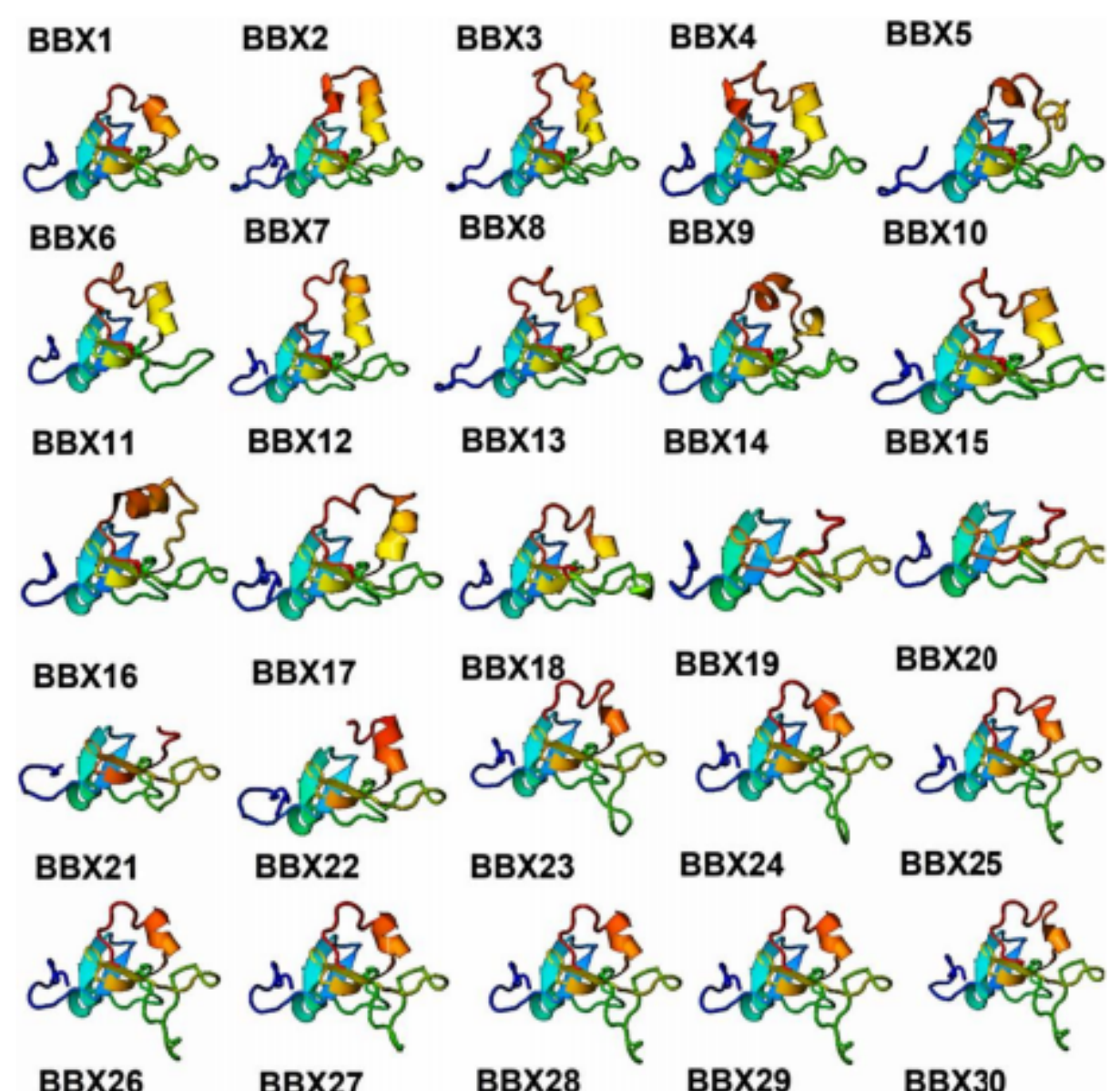

$\begin{array}{lllll}\text { BBX26 } & \text { BBX27 } & \text { BBX28 } & \text { BBX29 } & \text { BBX30 }\end{array}$

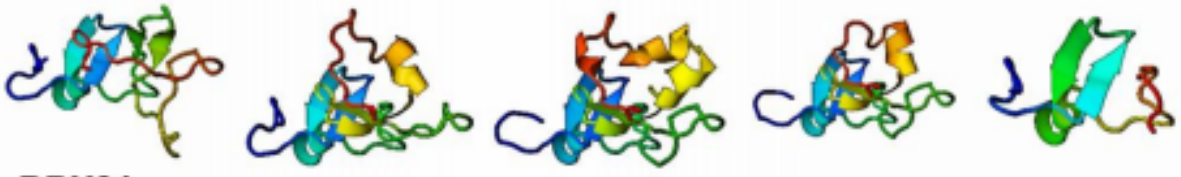

BBX31

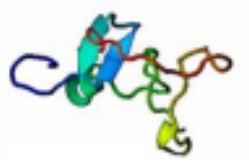

Figure 3

The predicted three-dimensional structure of tomato BBX proteins. 
A phylogenetic Tree

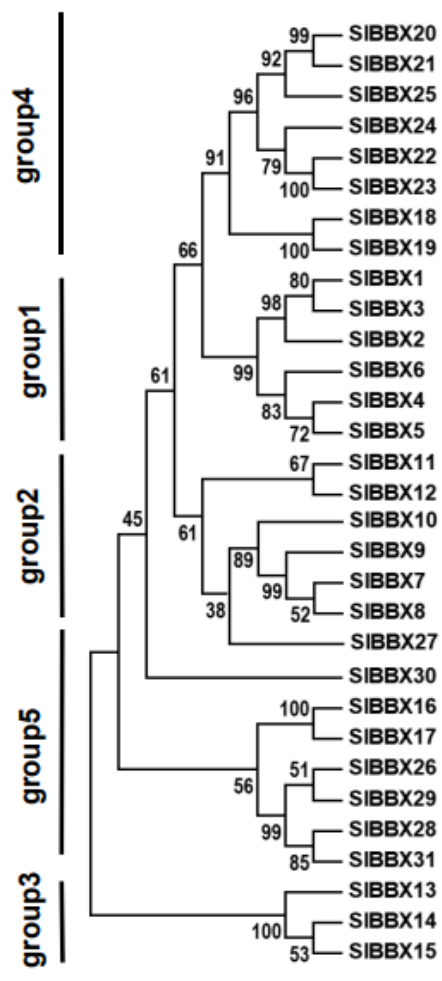

\section{B Gene Structure}

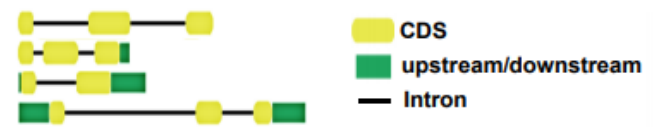

\section{Motif pattern}

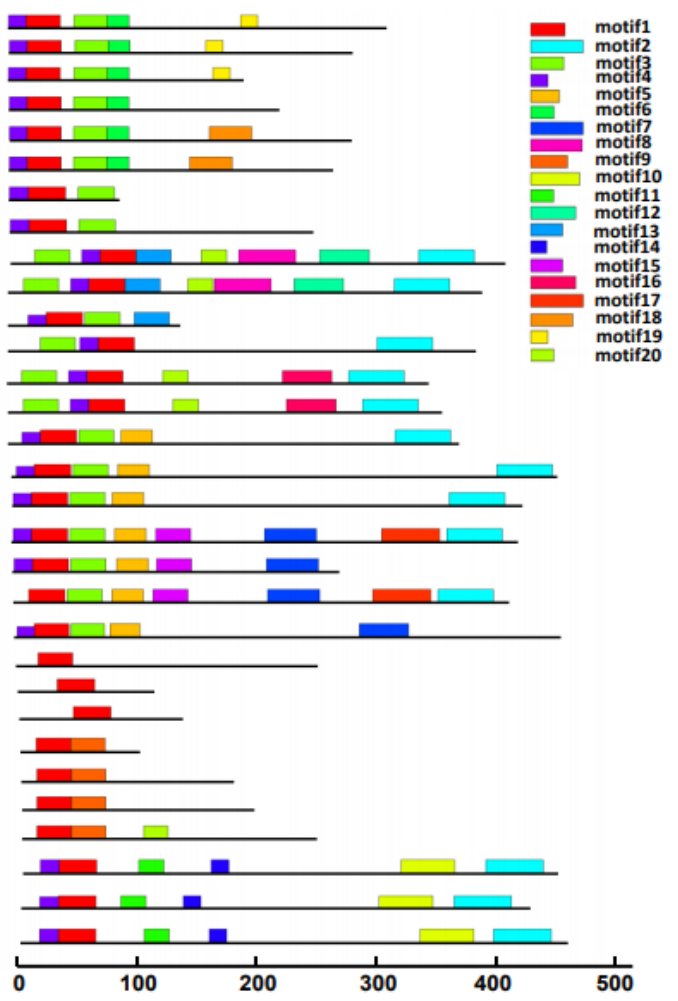

Figure 4

Phylogenetic relationship, gene structure and architecture of the conserved protein motifs in SIBBXs. a The phylogenetic tree was constructed based on the full-length sequences of SIBBX proteins. $b$ Exonintron structure of SIBBXs. Green boxes indicate untranslated 5'- and 3'-regions, yellow boxes indicate exons; and black lines indicate introns. c The motifs composition. The motifs, numbered 1-20, were displayed in different colored boxes. The sequence information for each motif is provided in Additional file 2: Table S1. 

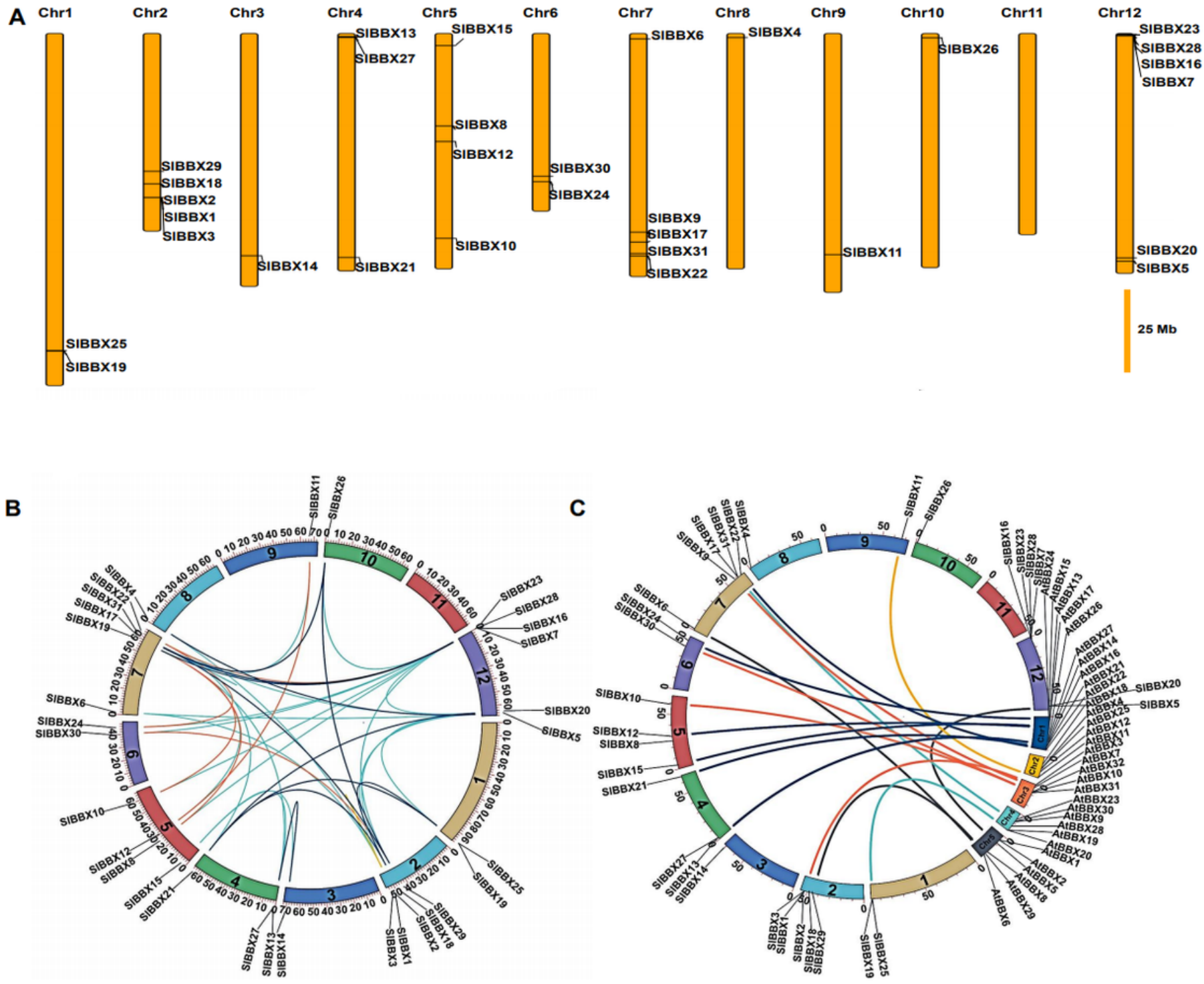

Figure 5

Chromosome distribution and syntenic analysis of SIBBX genes in tomato. a Positions of SIBBX genes family members on tomato chromosomes. b Segmental duplication of tomato BBX genes. Gene pairs located in the segmental duplicated chromosomal regions were linked using different lines. c Syntenic analysis of tomato and Arabidopsis BBX genes. Colored curves denote the syntenic relationships between tomato and Arabidopsis BBX gens. 


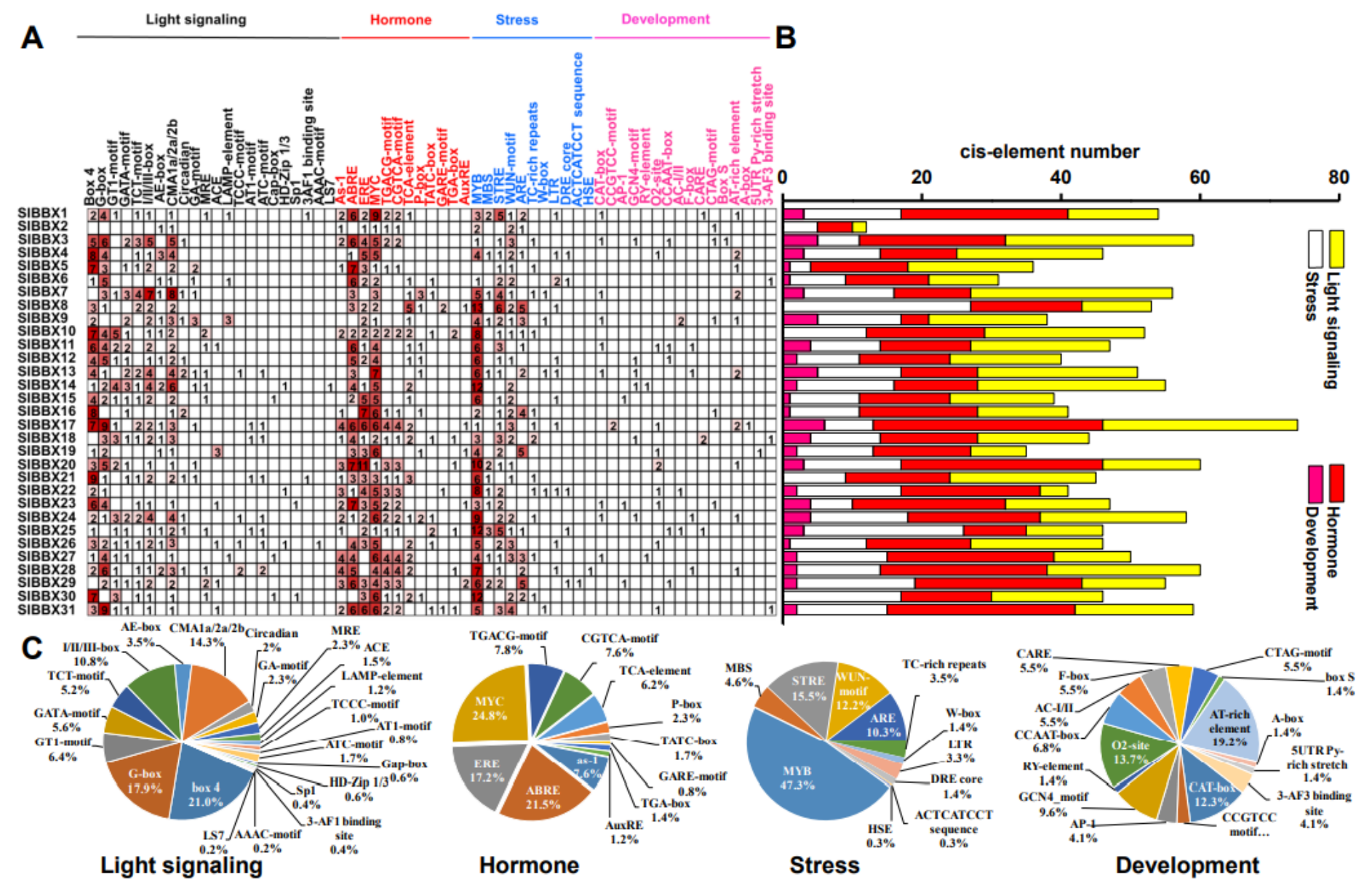

\section{Figure 6}

Inspection of cis-acting elements in tomato BBX genes. a The numbers of different promoter elements in these SIBBX genes were indicated by different colors and numbers of the grid. $b$ The sum of the cisacting elements in each category was represented by different colored histograms. c Pie charts with different sizes represented the ratio of each promoter element in each category. 



Figure 7

Gene expression of SIBBXs in tomato leaves after the exposure of plants to different light quality for $6 \mathrm{~h}$ from dark. Light quality treatments include dark (D), white light $(W)$ or purple $(P)$, blue (B), green $(G)$, yellow $(Y)$, red $(R)$ and far-red (FR) light. The light intensity was $100 \mu \mathrm{mol} m-2 \mathrm{~s}-1$. Data are presented as the means of three biological replicates $( \pm S D)$. Different letters indicate significant differences $(P<0.05)$ according to Tukey's test. 


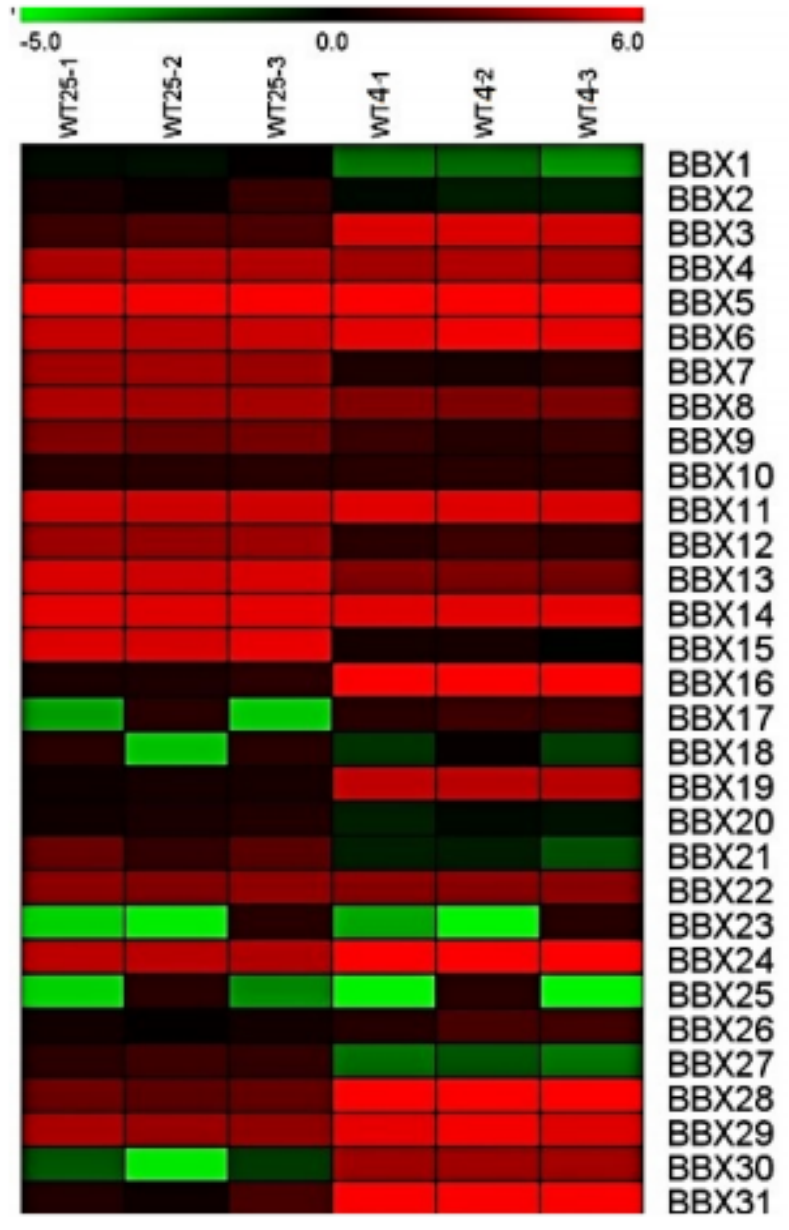

\section{Figure 8}

Gene expression of SIBBXs in tomato plants after exposure to low temperature (4 oC) for $6 \mathrm{~h}$. FPKM values were used to generate the heatmap. The scale represents the relative signal intensity of the FPKM values.

\section{Supplementary Files}

This is a list of supplementary files associated with this preprint. Click to download.

- Table12.pdf

- SupplementarytablesS1S2.pdf

- SupplementaryFiguresS1S4.pdf 